\title{
High diversity of chromosomal aberrations in a Brazilian myelodysplastic syndrome cohort
}

\author{
C.L. Ribeiro ${ }^{1,2}$, I.P. Pinto ${ }^{1,2}$, M.O. Diogo ${ }^{2,3}$, D.M. da Cruz e \\ Cunha $^{2}$, L.B. Minasi, ${ }^{2,3}$, F.S.M. Kluthcouski ${ }^{4}$, A.D. da Cruz ${ }^{1,2,3,5}$ \\ and C.C. da Silva $a^{1,2,3,5}$ \\ ${ }^{1}$ Programa de Pós-graduação em Biotecnologia e Biodiversidade, \\ Universidade Federal de Goiás, Goiânia, GO, Brasil \\ ${ }^{2}$ Grupo de Pesquisa Replicon, Departamento de Agricultura e \\ Ciências Biológicas, Pontifícia Universidade Católica de Goiás, \\ Goiânia, GO, Brasil \\ ${ }^{3}$ Programa de Mestrado em Genética, Pontifícia Universidade \\ Católica de Goiás, Goiânia, GO, Brasil \\ ${ }^{4}$ Departamento de Hematologia, Hospital das Clínicas da \\ Universidade Federal de Goiás, Goiânia, GO, Brasil \\ ${ }^{5}$ Laboratório de Citogenética Humana e Genética Molecular, \\ Secretaria de Saúde Pública do Estado de Goiás, Goiânia, GO, Brasil \\ Corresponding author: C.L. Ribeiro \\ E-mail: cristianoluiz@ pucgoias.edu.br
}

Genet. Mol. Res. 18 (2): gmr18322

Received April 09, 2019

Accepted May 21, 2019

Published June 24, 2019

DOI http://dx.doi.org/10.4238/gmr18322

\begin{abstract}
Myelodysplastic syndrome (MDS), an oncohematological disease, is characterized by distinct levels of peripheral blood cytopenia, cell differentiation dysplasia and various types of chromosomal alterations. The Revised International Prognostic Scoring System uses the GTG-banding karyotype as one of the main components for scoring patient prognosis in MDS. Using GTG-banding karyotyping, we looked for chromosomal alterations in bone marrow samples obtained from a cohort of Brazilian patients in Goiás state, Brazil.
\end{abstract}


Numerical and/or structural chromosomal alterations were detected in 15 of 29 patients. A total of 23 clones with the chromosomal alterations were obtained, of which 12 were numerical and 11 were structural. Complete trisomies were observed in five clones, complete monosomies in three clones, triploidies in three clones, and one clone contained a marker chromosome. Among the clones with structural alterations, two clones had a partial trisomy in 1q, five clones had partial monosomies, one clone contained an isochromosome, and three clones showed reciprocal translocations. The high diversity of chromosomal alterations is inherent to the strong degree of chromosomal and genomic instability in this myeloid disease. These alterations can be associated with the activation or inhibition of gene expression, leading to the deregulation of critical cell viability functions and hence ineffectiveness of hematopoiesis in MDS. Our study is the first to identify chromosomal alterations associated with this poorly studied disease in central Brazil.

Key words: Myelodysplastic syndrome; Karyotype; Chromosomal alterations; Phenotypes

\section{INTRODUCTION}

Myelodysplastic syndrome (MDS), a heterogeneous group of clonal oncohematological diseases that involve the hematopoietic stem cells, causes several alterations in the hematopoietic process (Visconte et al., 2015). MDS presents with varying degrees of bone marrow failure and can evolve to different levels of cytopenia in the peripheral blood, with distinct clinical manifestations, including an increased risk of progression to acute myeloid leukemia (AML) (Font et al., 2012).

The estimated incidence of MDS is 4 in 100,000 individuals per year in the general population and increases significantly in the elderly, reaching 50 in 100,000 individuals more than 80 years of age (Neukirchen et al., 2011). The mean age of onset of the disease is 60 years (Greenberg et al., 2012), and only $10 \%$ of the patients are less than 50 years old (Neukirchen et al., 2011; Lubeck et al., 2016).

Numerical (e.g., $-5,-7,+8,+21$ ) and structural (e.g., 5q-, 7q-, 12p-, 13q-, $17 \mathrm{p}-$, and $20 \mathrm{q}-$ ) chromosomal alterations are detected in $40-60 \%$ of cases of primary MDS. The identification of chromosomal alterations is crucial for the prognosis and biological understanding of MDS (Bejar, 2013). Secondary MDS generally affects younger individuals and is related to exposure to occupational and/or environmental cytotoxic and genotoxic agents. The chromosomal alterations in secondary MDS are more complex and observed in up to $90 \%$ of cases. Compared with primary MDS, the inherent risk of transformation from secondary MDS to AML is higher and the prognosis is worse (Estephan and Tiu, 2014). 
The International Working Group for the Prognosis of MDS has proposed a refined MDS classification score that integrates clinical, laboratory, and morphological variables; this is the basis for the Revised International Prognostic Scoring System (IPSS-R) (Greenberg et al., 2012). The currently more commonly used IPSS-R categorizes patients into five different risk groups (ranging from very low to very high), corresponding to a better assessment of the set of clinical laboratory markers and a better understanding of the biological processes underlying the development and progression of MDS (Greenberg et al., 2012).

The chromosomal and genomic instabilities associated with MDS causes an accumulation of mutations observed in this hematological disorder. At least $78 \%$ of patients with MDS carry somatic mutations that are potentially associated with the transformation and progression of the disease (Papaemmanuil et al., 2013). The classification of chromosomal alterations that have not yet been elucidated by previous reports could define an adverse risk. Therefore, additional studies are required for their subclassifications, since they tend to define the cytogenetic risk as being intermediate (Giagounidis and Haase, 2013). Cytogenetic studies are important and necessary to contribute to biological studies related to the etiology, transformation, and malignization of the MDS phenotypes (Greenberg et al., 2012; Malcovati et al., 2013). Along this line, we examined the chromosomal alterations in a cohort of patients with primary MDS, using conventional methodologies (viz. GTG-banding karyotyping).

\section{MATERIAL AND METHODS}

This study was conducted at the Replicon Research Group of the School of Agrarian and Biological Sciences of the Pontifical Catholic University of Goiás in collaboration with the Human Cytogenetics and Molecular Genetics Laboratory of the Dr. Giovanni Cysneiros Public Health State Laboratory (LACEN-GO) of the Health Secretary of Goiás. For each of the 32 patients with primary MDS, a total of $4 \mathrm{~mL}$ of bone marrow sample was collected by the attending physician in a standardized bone marrow collection system. All patients voluntarily signed an Informed Consent Form before being included in the cohort. The study was approved by the Human Research Ethics Committee of the Clinical Hospital of the Federal University of Goiás (Protocol No. 1.621.064/2016).

\section{Cytogenetic Analysis}

Karyotyping with a resolution of $>450$ bands was performed using standard cell culture and GTG-banding procedures, according to the protocols of Verma and Babu (1995), with slight modifications. The cytogenetic analysis was performed on bone marrow cells of patients with MDS. Short-term cultures $(48 \mathrm{~h})$ were started by incubating $1.0 \mathrm{~mL}$ of the cell sample in $5 \mathrm{~mL}$ of RPMI 1640 medium (Gibco ${ }^{\circledR}$ Life Science, USA), supplemented with $1 \mathrm{~mL}$ of fetal bovine serum (Gibco ${ }^{\circledR}$ Life Science, USA) and $100 \mu \mathrm{L}$ of L-glutamine (Gibco ${ }^{\circledR}$ Life Science, USA) at $37^{\circ} \mathrm{C}$ under $5 \% \mathrm{CO}_{2}$. Mitotic divisions were arrested at metaphase by the addition of $100 \mu \mathrm{L}$ of a $10 \mu \mathrm{g} / \mathrm{mL}$ 
aqueous colchicine solution (Gibco ${ }^{\circledR}$ Life Science, USA) and incubation for $30 \mathrm{~min}$ before harvesting the cell suspension. The cells were incubated in a hypotonic $\mathrm{KCl}$ solution $(0.075 \mathrm{M})$ for $30 \mathrm{~min}$ at $37^{\circ} \mathrm{C}$, following which the suspended cells were fixed with a methanol/glacial acetic acid solution (3:1), which was added dropwise. The cells were then mixed, pelleted by centrifugation, and resuspended in fresh fixative solution. The fixation step was repeated 3-4 times. The fixed cells were then dripped onto clean microscope slides to be analyzed by GTG-banding.

For each sample, 20 metaphases were analyzed. The images of the metaphases were captured using an AxioImager $2^{\circledR}$ microscope (Carl Zeiss, Germany) connected to a Metafer $4{ }^{\circledR}$ slide scanning platform (Metasystems Corporation, Germany). Chromosomal analysis was performed using IKAROS $^{\circledR}$ software (Metasystems Corporation, Germany).

\section{Statistical Analysis}

Statistical tests were performed for establishing 95\% confidence intervals and

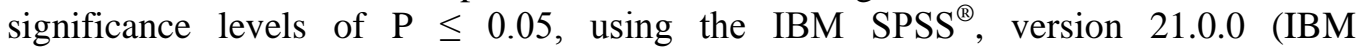

Corporation, Armonk, NY, USA). Correlations were determined using Spearman's correlation coefficients for non-parametric data.

\section{RESULTS}

The cytogenetic analysis was performed using bone marrow samples from 32 patients with primary MDS in central Brazil. The cohort comprised 23 females and 9 males, with a mean age of 53.8 years (range 26 - 75 years) for the females and 55.1 years (range 34 - 79 years) for the males. In this case series, three samples were not informative owing to non-clonal expansion of the bone marrow cells in culture and were therefore excluded from the subsequent analyses. In the final patient cohort, 15 of 29 patients showed numerical and/or structural chromosomal alterations in their karyotypes, whereas 14 of 29 patients had no such alterations (Table 1). Our small sample size can be explained by the reduced incidence of MDS in the Brazilian population. In this cohort, risk prediction showed positive correlations with the patient's age $(r=0.507, P=0.005)$, number of blasts in the bone marrow $(r=0.476, P=0.009)$, cytogenetic risk $(r=0.826, P<0.0001)$, and clinical outcome $(r=0.479, P=0.009)$.

Upon clonal expansion of the bone marrow cells, 23 clones were found to be related to the chromosomal alterations acquired in this cohort of patients, of which 12 were numerical and 11 were structural. Complete trisomies were observed in five clones, complete monosomies in three clones, and triploidies in three clones, and a marker chromosome was found in one clone. Among the clones with structural alterations, a partial trisomy in 1q was observed in two clones, a partial monosomy in five clones, an isochromosome in one clone, and a reciprocal translocation in three clones (Table 2). 
Table 1. Risk estimates, according to the International Prognostic Scoring System - Revised (IPSS-R), of a cohort of patients with myelodysplastic syndrome and their clinical outcomes.

\begin{tabular}{|c|c|c|c|c|c|c|c|c|c|c|}
\hline Patient & Gender & $\begin{array}{l}\text { Age } \\
\text { (years) }\end{array}$ & Cytopenias & $\begin{array}{l}\text { Blasts bone } \\
\text { marrow } \\
(\%)\end{array}$ & Karyotype notation* & $\begin{array}{l}\text { IPSS-R } \\
\text { cytogenetic } \\
\text { risk }\end{array}$ & $\begin{array}{l}\text { IPSS-R } \\
\text { Score }^{\#}\end{array}$ & $\begin{array}{l}\text { IPSS-R } \\
\text { age-adjusted } \\
\text { risk }\end{array}$ & $\begin{array}{l}\text { Risk } \\
\text { prediction }\end{array}$ & $\begin{array}{l}\text { Clinical } \\
\text { outcome }\end{array}$ \\
\hline$\overline{\text { MDSp1 }}$ & $\mathrm{F}$ & 65 & Erythropenia & 0 & mos polyploidy[1]/46,XX[19] & Intermediate & 3.5 & 3.34 & Intermediate & Death \\
\hline MDSp2 & $\mathrm{F}$ & 52 & Thrombocytopenia & 2 & $46, \mathrm{XX}[20]$ & Good & 1 & 0.19 & Very low & Death \\
\hline MDSp3 & $\mathrm{F}$ & 49 & Leukopenia & 0 & $46, X X[20]$ & Good & 1 & 0.05 & Very low & Stable \\
\hline MDSp4 & $\mathrm{F}$ & 42 & $\begin{array}{l}\text { Thrombocytopenia } \\
\text { Erythropenia }\end{array}$ & 0.5 & $46, X X[20]$ & Good & 1 & -0.26 & Very low & Stable \\
\hline MDSp5 & M & 57 & $\begin{array}{l}\text { Leukopenia } \\
\text { Thrombocytopenia }\end{array}$ & 0.5 & $46, X Y[20]$ & Good & 2.5 & 2.01 & Low & Stable \\
\hline MDSp6 & $\mathrm{F}$ & 65 & $\begin{array}{l}\text { Erythropenia } \\
\text { Thrombocytopenia }\end{array}$ & 5 & $\operatorname{mos} 47, \mathrm{XX},+17[2] / 47, \mathrm{XX},+21[3] / 46, \mathrm{XX}[5]$ & Intermediate & 4 & 3.85 & Intermediate & AML \\
\hline MDSp7 & $\mathrm{F}$ & 57 & Thrombocytopenia & 4.5 & $\operatorname{mos} 45, \mathrm{XX}, \mathrm{t}(4 ; 11)(\mathrm{q} 21 ; \mathrm{q} 23)[15] / 46, \mathrm{XX}[5]$ & Intermediate & 3 & 2.55 & Low & Stable \\
\hline MDSp8 & $\mathrm{F}$ & 26 & Thrombocytopenia & 0 & Not informative** & nd & nd & nd & nd & Stable \\
\hline MDSp9 & M & 54 & $\begin{array}{l}\text { Thrombocytopenia } \\
\text { Erythropenia }\end{array}$ & 2 & $\begin{array}{l}\text { Not informative** } \\
\text { mos }\end{array}$ & nd & nd & nd & nd & Stable \\
\hline MDSp10 & M & 79 & $\begin{array}{l}\text { Leukopenia } \\
\text { Thrombocytopenia }\end{array}$ & 5 & \multicolumn{2}{|l|}{$\begin{array}{l}\operatorname{mos} \\
46, X Y, \operatorname{add}(1)(\mathrm{q} ?)[20] / 47, \mathrm{XY}, \operatorname{add}(1)(\mathrm{q} ?),+8[6 \mathrm{Bad} \\
\text { ]/Polyploidy[3] }\end{array}$} & 6.5 & 6.66 & Very high & Stable \\
\hline MDSp11 & M & 34 & Thrombocytopenia & 0 & Not informative** & nd & nd & nd & nd & Stable \\
\hline MDSp12 & $\mathrm{F}$ & 73 & Leukopenia & 0 & $46, X X[20]$ & Good & 1 & 1.14 & Very low & Stable \\
\hline MDSp13 & $\mathrm{F}$ & 42 & Thrombocytopenia & 0 & $46, X X[20]$ & Good & 1 & -0.26 & Very low & Stable \\
\hline MDSp14 & $\mathrm{F}$ & 75 & $\begin{array}{l}\text { Thrombocytopenia } \\
\text { Erythropenia }\end{array}$ & 0 & $46, X X[20]$ & Good & 1 & 1.23 & Very low & Stable \\
\hline MDSp15 & $\mathrm{F}$ & 60 & $\begin{array}{l}\text { Leukopenia } \\
\text { Thrombocytopenia }\end{array}$ & 0 & $46, \mathrm{XX}[20]$ & Good & 2.5 & 2.13 & Low & Stable \\
\hline MDSp16 & $\mathrm{F}$ & 52 & $\begin{array}{l}\text { Erythropenia } \\
\text { Leukopenia }\end{array}$ & 6.5 & $\operatorname{mos} 47, \mathrm{XX},+15[5] / 46, \mathrm{XX}[15]$ & Intermediate & 5.5 & 5.1 & High & AML \\
\hline MDSp17 & $\mathrm{F}$ & 72 & Leukopenia & 0 & $\begin{array}{l}\operatorname{mos} 45, \mathrm{X},-\mathrm{X}[2] / 46, \mathrm{XX}[18] \\
\operatorname{mos}\end{array}$ & Intermediate & 3.5 & 3.57 & Intermediate & Stable \\
\hline MDSp18 & $\mathrm{F}$ & 62 & Leukopenia & 0 & $\begin{array}{l}46, X X, \operatorname{del}(12)(q 23 \text { àqter })[2] / 47, X X,+22[2] / 46 \\
\text {,XX[16] }\end{array}$ & Intermediate & 2 & 1.68 & Low & Stable \\
\hline MDSp19 & M & 40 & Thrombocytopenia & 0 & $46, X Y[20]$ & Good & 1 & -0.35 & Very low & Stable \\
\hline MDSp20 & M & 67 & $\begin{array}{l}\text { Leukopenia } \\
\text { Thrombocytopenia }\end{array}$ & 0 & $\operatorname{mos} 46, X Y, \operatorname{del}(11)(q 13 a ̀ q t e r)[10] / 46, X Y[11]$ & Very good & 0 & -0.15 & Very low & Stable \\
\hline MDSp21 & $\mathrm{F}$ & 72 & Leukopenia & 0 & $\begin{array}{l}\operatorname{mos} \\
46, X X, \operatorname{del}(10)(q 23 \text { àqter)[2]/Polyploidy[1]/46 } \\
\text { XX[17] }\end{array}$ & Bad & 2 & 2.08 & Low & Stable \\
\hline MDSp22 & $\mathrm{F}$ & 40 & $\begin{array}{l}\text { Leukopenia } \\
\text { Thrombocytopenia }\end{array}$ & 0 & $46, X X[20]$ & Good & 1 & -0.35 & Very low & Stable \\
\hline MDSp23 & $\mathrm{F}$ & 39 & $\begin{array}{l}\text { Leukopenia } \\
\text { Erythropenia }\end{array}$ & 0 & $46, X X[20]$ & Good & 1.5 & 0.18 & Very low & Stable \\
\hline MDSp24 & $\mathrm{F}$ & 38 & Leukopenia & 0 & $\operatorname{mos} 46, \mathrm{XX}, \mathrm{t}(3 ; 10)(\mathrm{q} 29 ; \mathrm{q} 25)[1] / 46, \mathrm{XX}[19]$ & Intermediate & 3 & 1.8 & Low & Stable \\
\hline $\operatorname{MDSp} 25$ & $\mathrm{~F}$ & 49 & $\begin{array}{l}\text { Leukopenia } \\
\text { Erythropenia }\end{array}$ & 0 & $46, \mathrm{XX}[20]$ & Good & 1 & 0.05 & Very low & Stable \\
\hline MDSp26 & $\mathrm{F}$ & 74 & $\begin{array}{l}\text { Leukopenia } \\
\text { Thrombocytopenia }\end{array}$ & 0 & $\begin{array}{l}\operatorname{mos} \\
46, X X, \operatorname{add}(1)(\mathrm{q} 32), \mathrm{i}(17)(\mathrm{q} 10)[11] / 46, \mathrm{XX}[9]\end{array}$ & Intermediate & 4 & 4.12 & Intermediate & Death \\
\hline MDSp27 & M & 65 & $\begin{array}{l}\text { Erythropenia } \\
\text { Leukopenia }\end{array}$ & 0 & $46, X Y[20]$ & Good & 2 & 1.8 & Low & Stable \\
\hline MDSp28 & M & 60 & $\begin{array}{l}\text { Erythropenia } \\
\text { Thrombocytopenia }\end{array}$ & 6 & $\begin{array}{l}\operatorname{mos} 45, \mathrm{XY},- \\
17[1] / 47, \mathrm{XY},+21[3] / 46, \mathrm{XY}, \operatorname{del}(7 \mathrm{q})[5] / 47, \mathrm{XY} \\
,+\operatorname{mar}[1] / 46, \mathrm{XY}[11]\end{array}$ & Very bad & 7 & 6.85 & Very high & AML \\
\hline MDSp29 & $\mathrm{F}$ & 54 & $\begin{array}{l}\text { Erythropenia } \\
\text { Leukopenia }\end{array}$ & 0 & $\operatorname{mos} 46, \mathrm{XX}, \mathrm{t}(8 ; 16)(\mathrm{q} 22 ; \mathrm{q} 22)[2] / 46, \mathrm{XX}[18]$ & Intermediate & 3 & 2.44 & Low & Stable \\
\hline MDSp30 & M & 40 & $\begin{array}{l}\text { Erythropenia } \\
\text { Leukopenia }\end{array}$ & 0 & $45, \mathrm{X},-\mathrm{Y}[18] / 46, \mathrm{XY}[2]$ & Very good & 1.5 & 0.23 & Very low & Stable \\
\hline MDSp31 & $\mathrm{F}$ & 39 & Erythropenia & 0 & $\operatorname{mos} 46, \mathrm{XX}, \operatorname{del}(5)(\mathrm{q} 13 \mathrm{q} 33)[3] / 46, \mathrm{XX}[17]$ & Good & 1 & -0.4 & Very low & Stable \\
\hline MDSp32 & $\mathrm{F}$ & 40 & Erythropenia & 0 & $46, \mathrm{XX}[20]$ & Good & 2 & 0.8 & Very low & Stable \\
\hline
\end{tabular}

F: Female; M: Male; nd: not defined; AML: Acute myeloid leukemia. IPSS-R: International Prognostic Scoring System -

Revised. "ISCN2016: An international system for human cytogenomic chromosome nomenclature. ${ }^{* *}$ Not informative: Karyotype analysis not performed owing to non-clonal expansion of the bone marrow samples of the patient. "Estimated score according to hemoglobin levels, absolute neutrophil count, platelet count, percentage of blasts in the bone marrow, and cytogenetic risk. 
Table 2. Distribution of clones according to the chromosomal alterations in a cohort of patients with primary myelodysplastic syndrome from the public health-care system of Goiânia-GO (Brazil) dedicated to hematologic diseases.

\begin{tabular}{|c|c|c|c|}
\hline Chromosomal alterations & Description & Clones with alterations & $\mathbf{n}$ \\
\hline \multirow{10}{*}{ Numerical } & Trisomy & 8 & 1 \\
\hline & & 17 & 1 \\
\hline & & 21 & 1 \\
\hline & & $+15^{*}$ & 1 \\
\hline & & 22 & 1 \\
\hline & Total monosomies & $-\mathrm{Y}$ & 1 \\
\hline & & $-\mathrm{X}$ & 1 \\
\hline & & -17 & 1 \\
\hline & Euploidies & Triploidies & 3 \\
\hline & Small supernumerary chromosome & Marker* & 1 \\
\hline \multirow[t]{11}{*}{ Structural } & Translocations & $\mathrm{t}(3 ; 10)(\mathrm{q} 29 ; \mathrm{q} 25)^{*}$ & 1 \\
\hline & & $\mathrm{t}(4 ; 11)(\mathrm{q} 21 ; \mathrm{q} 23)$ & 1 \\
\hline & & $\mathrm{t}(8 ; 16)(\mathrm{q} 22 ; \mathrm{q} 22)^{*}$ & 1 \\
\hline & Isochromosome & $\mathrm{i}(17)(\mathrm{q} 10)$ & 1 \\
\hline & Gains & $\operatorname{add}(1)(q ?)$ & 1 \\
\hline & & $\operatorname{add}(1)(\mathrm{q} 32)$ & 1 \\
\hline & Losses & $\operatorname{del}(5)(\mathrm{q} 13 \mathrm{q} 33)$ & 1 \\
\hline & & $\operatorname{del}(7 \mathrm{q}-)$ & 1 \\
\hline & & $\operatorname{del}(10)(q 23 a ̀ q t e r)$ & 1 \\
\hline & & del(11)(q13àqter) & 1 \\
\hline & & $\operatorname{del}(12)(q 23 a ̀ q t e r)$ & 1 \\
\hline Total & & & 23 \\
\hline
\end{tabular}

*There are no previous reports of the association of these numerical and structural chromosome changes with primary myelodysplastic syndrome.

\section{DISCUSSION}

The cases included in the present study were obtained by sampling for convenience and voluntary adherence. In this cohort, the disease was more frequent in females, with a ratio of 1:2.5 and the mean age at diagnosis was 53.8 years. These findings were not in agreement with those of Bănescu et al. (2011) and Dao (2017) who found that male are affected more than females with a male/female ratio of 1.44 to 1 and 1.26 to 1 , respectively. Despite data from population-based registries on the incidence and prevalence of MDS, other reports also show a predominance of the disease in males (Gologan, 2010; Neukirchen et al., 2011; Lubeck et al., 2016).

In our study, GTG-banding was useful for defining the cytogenetic risk of 29 of the original 32 patient cohort, with 15 of the final study cohort showing numerical and/or structural alterations that defined the cytogenetic risk as ranging from very good to very bad. Proportionally, one in two cases of primary MDS show karyotypic alterations that are useful for establishing genetic risk, and this is thus an important variable for predicting the final risk for the patient as well as for therapeutic decisions. Therefore, the karyotype turned out to be one of the most important prognostic parameters and was incorporated into statistical models aiming for a better prediction of the individual prognosis, such as the Revised International Prognostic Scoring System (Haase, 2008; Greenberg et al., 2012). The numerical and/or structural chromosomal alterations identified were associated with biological processes related to the etiology, transformation, and malignization of the disease phenotypes (Prebet et al, 2011; Adès et al., 2014). Overall, the clones containing the acquired chromosomal alterations presented numerical and structural alterations at 
approximate rates, and these are both important events in the progression of primary MDS. Previous reports have considered that the pathogenic model of the onset and progression of primary MDS includes multiple stages that are dependent on genomic instability and the accumulation of genetic alterations over the course of the disease (Steidl et al., 2005; Bănescu et al., 2011).

Using clinical laboratory variables, such as hemoglobin levels, absolute neutrophil counts, platelet counts, percentage of blasts in the bone marrow, and cytogenetic risk, in addition to the age of the patient, it was possible to establish that the variables taken together could define the risk prediction for each case (Table 1). The age, number of blasts in the bone marrow, cytogenetic risk, and clinical outcome variables of the patient all correlated with risk prediction. Among these, the cytogenetic alteration was the variable that most contributed to this correlation, in agreement with previous reports (Steidl et al., 2005; Bănescu et al., 2011).

Although we had a small sample size, it was possible to conclude from this cohort analysis that risk prediction does not always reflect the clinical outcome of primary MDS, since one patient with a very low-risk prediction had died whereas another patient with a very high-risk prediction remained stable. Although the cytogenetic risk is a good variable for inferring on risk prediction, additional genomic studies (e.g., microarray and sequencing analyses) should be performed, since 50\% of MDS cases do not show karyotype alterations, which is what we also found in our study (Bejar et al., 2011; Prebet et al, 2011).

On the other hand, a risk prediction categorized as "intermediate" should command special attention from researchers and the attending clinicians, since the patients in this category evolved to death and AML, although one patient remained stable. This observation suggests that there is much to be elucidated about the "intermediate" category of risk prediction for primary MDS. These findings are in agreement with those of other authors who suggested that despite recent advances in diagnostic approaches, primary MDS continues to show extensive variability in its clinical course, often contrary to the initial prognosis (Cazzola and Malcovati, 2010; Giagounidis and Haase, 2013; Greenberg et al., 2013).

With regard to total aneuploidies, trisomies were detected in five clones, whereas monosomies were present in three clones. On the other hand, among the partial aneuploidies, segmental monosomies were more frequent than segmental trisomies. In general, partial or complete chromosomal trisomies can alter gene expression levels and cause gene overexpression, affecting important cell-cycle regulation events and altering processes associated with biological pathways that influence cell viability in MDS (Zahid et al., 2017).

The contribution of the partial trisomy of the long arm of chromosome 1 still requires additional studies to understand its potential role in the progression of primary MDS. In our study, two chromosomal gains were identified in the long arm of chromosome 1. Although these chromosomal alterations are rarely reported in primary MDS, gains in 1q result in partial segmental trisomy, most likely due to interstitial duplications of the affected regions. Bacher et al. (2015) reported that duplications of 1q occur mainly as a secondary event in MDS. On the other hand, Alfaro et al. (2008) reported a dup(1)(q21q32) in two patients with primary MDS, in agreement with the findings of our study. In their study, one patient showed clonal cytogenetic progression with trisomy of chromosome 8, and the other patient evolved to AML. In our study, clones with add(1)(q?) only and clones with 
add(1)(q?) combined with trisomy of chromosome 8 were identified, and the patient was stable at the end of the study even though he was classified as being at very high risk. In our study, the second patient showed a gain in 1q32 and i(17)(q10), classified as intermediate cytogenetic risk, and did not survive.

Trisomy of chromosome 8 is a cytogenetic abnormality that is frequently acquired in myeloid malignancies, occurring in approximately $5 \%$ of patients with primary MDS, and it correlates with very high risk (Schanz et al., 2012). Cells with trisomy of chromosome 8 in MDS express high levels of antiapoptotic proteins and present strong resistance to apoptotic stimuli (Sloand et al., 2007). The overexpression of antiapoptotic proteins confers a survival advantage to clones with this trisomy over that of normal hematopoietic precursor cells in the bone marrow microenvironment. Therefore, they represent a poor prognostic marker for hematopoietic progression in patients with MDS (Sloand et al., 2005; Zahid et al., 2017). In our study, one patient showed trisomy of chromosome 8 with mosaic polyploidy and gain in 1q. Although the patient was classified as being at very high risk, he remained stable, different from previous reports on the aggressiveness of MDS in cases of trisomy of chromosome 8 .

The trisomy of chromosome 21 is more frequent in AML than in MDS (Grimwade et al., 2010). Approximately $0.3-0.8 \%$ of MDS cases show this trisomy and it is classified as an unusual cytogenetic alteration in the disease, being associated with a poor prognosis and presenting a much more aggressive and rapid leukemic transformation (Sole et al., 2005; Schanz et al., 2012; Adès et al., 2014; Zahid et al., 2017). Patients with MDS with trisomy 21-bearing clones classically show low absolute neutrophil counts with mild anemia and thrombocytopenia (Sole et al., 2005; Schanz et al., 2012). The findings of our study are similar to those of previous reports, since one patient showed trisomy of chromosomes 21 and 17, exhibiting erythropenia and thrombocytopenia, with a moderate risk prediction, evolving to AML.

Events involving chromosome 17 have been considered relevant and are widely reported, as it includes the $17 \mathrm{p} 13.1$ cytoband in which the tumor suppressor gene TP53 is located. According to Adès et al. (2014), TP53 encodes a 53-kDa nuclear phosphoprotein with tumor suppression activity, containing activation and transcriptional regulation domains. The TP53 protein regulates the expression of several target genes, inducing cell cycle control, apoptosis, cell senescence, and DNA repair (Jasek et al., 2010). Deleterious mutations in one or both alleles of TP53 can deregulate several molecular pathways involved in approximately 50\% of human cancers and 20\% of onco-hematological malignancies, including MDS, having a negative effect on patient survival (Jasek et al., 2010; Shih et al., 2013). In our study, a patient with a complex karyotype (including a clone with monosomy of chromosome 17) and very poor cytogenetic risk progressed to AML.

One clone with trisomy of chromosome 22 and another clone with a supernumerary marker chromosome were observed in distinct patients in our study. In addition to these aneuploidies, a trisomy of chromosome 15 was identified in one patient. These findings were not previously reported in cohorts of patients with primary MDS. The patient with a trisomy of chromosome 15 was classified as being at high risk, with $6.5 \%$ of blasts in the bone marrow, and progressed to AML. Additional cases should be analyzed to better understand the role of chromosome 15 in the aggressiveness of MDS. The analysis of uncommon and poorly reported karyotypes assists in the identification of chromosomal abnormalities and candidate regions that can harbor genes associated with the progression 
of MDS, and contributes to the identification of potential targets for future therapeutic interventions.

In general, according to the IPSS-R criteria, chromosome translocations acquired in MDS tend to define the cytogenetic risk as being intermediate. In our study, translocations were observed in approximately $10 \%$ of the patients, and all were included in the intermediate cytogenetic risk category and remained stable until the end of the study. However, the identification and reporting of chromosome translocations is essential in order to provide insight into the mechanisms of MDS pathogenesis. New and recurrent translocations have been reported in several patients, but only a few studies have addressed the prognostic relevance of such chromosome translocations (Nomdedeu et al., 2016). In our study, the chromosomal translocations $\mathrm{t}(8 ; 16)(\mathrm{q} 22 ; \mathrm{q} 22)$ and $\mathrm{t}(3 ; 10)(\mathrm{q} 29 ; \mathrm{q} 25)$, which are uncommon in MDS, and the previously reported $\mathrm{t}(4 ; 11)(\mathrm{q} 21 ; \mathrm{q} 23)$ were detected. The truncated proteins that arise from the expression of genes located at the chromosomal breakpoints can act as transcription factors to alter the expression of several target genes, deregulating the molecular biological pathways, which is potentially leukemogenic (Gómez-Seguí et al., 2013).

According to Emerenciano et al. (2014), multiple chromosomal translocations involving chromosome 11 are associated with acute lymphoid leukemias and AMLs. In agreement with our chromosomal findings, the $\mathrm{t}(4 ; 11)(\mathrm{q} 21 ; \mathrm{q} 23)$ translocation involving the region of chromosome 11 that includes the $M L L$ gene (11q23) has previously been associated with leukemogenesis in MDS and acute leukemias. According to Peterson et al. (2018), $M L L$ encodes a transcriptional coactivator that has an essential role in the regulation of gene expression during hematopoiesis. Mutations in $M L L$ alter gene expression in cells in the bone marrow microenvironment, blocking the maturation of hematopoietic precursor clones (Emerenciano et al., 2014). One patient in our study was classified as being at low risk, and although he had $4.5 \%$ of blasts in the bone marrow, the disease was stable at the end of the study.

Our study also included a patient with the deletion del(5q). According to Bernasconi et al. (1994) and Komrokji et al. (2013) del(5q) is a chromosome alteration that is frequently identified in MDS. As described by Eisenmann et al. (2009), the terminal deletion of $5 \mathrm{q}$ is associated with good patient prognosis and a low probability of leukemic transformation. This region is known for having genes encoding proteins that act as hematopoietic growth factors; for example, IL4, IL5, IRF1, IL3, CSF-2, IL9, EGR-1, CD14, and $C S F-1 R$. The haploinsufficiency of these candidate genes can potentially affect hematopoiesis, leading to the development of dysplasias and cytopenias (Eisenmann et al., 2009). In addition, patients with low-risk, transfusion-dependent MDS with del(5q) responded well to lenalidomide (Butrym et al., 2015). Therefore, the detection of del(5q) is not only important for a precise diagnosis of MDS but also for the customized treatment of patients with this disease.

Deletions in $12 \mathrm{q}$ and $11 \mathrm{q}$, regions that harbor the $B T G 1$ and $C B L$ genes, respectively, are also reported in patients with MDS. BTG1 is a member of a family of antiproliferative genes that regulate cell growth and differentiation, whereas the $C B L$ gene product acts as a negative regulator of tyrosine kinase activator, a protein that is important for cell cycle regulation (Zahid et al., 2017). In our study, patients with the $\operatorname{del}(12)(\mathrm{q} 26 \rightarrow \mathrm{qter})$ and $\operatorname{del}(11)(\mathrm{q} 13 \rightarrow \mathrm{qter})$ clones had an intermediate and a very good cytogenetic risk, respectively, with a stable clinical outcome. This study also identified a 
deletion in the long arm of chromosome 10 in a region that harbors the FAS gene (viz., $\operatorname{del}(10)(q 23 \rightarrow q$ ter $)$ ), which is uncommon in MDS. This gene encodes a protein of the tumor necrosis factor receptor superfamily and has a central role in the physiological regulation of apoptosis (Feng et al., 2011). The process of apoptosis is increased at different stages of MDS, presumably as a result of differentiation defects.

Alterations in chromosome 7 are reported in approximately 10\% of MDS cases (Christiansen et al., 2004). Our study identified a patient with a deletion of the long arm of chromosome 7, who showed a very poor cytogenetic risk and progressed to AML. Deletion of the MLL5 gene located in 7q22 leads to impaired erythropoiesis and to a decrease in the repopulation capacity of hematopoietic progenitors in patients with MDS (Heuser et al., 2009). Considering this, the deletion del(7q) could lead to the haploinsufficiency of several other critical genes implicated in hematological malignancies, including MLL3, CUXI, and EZH2 (Hasegawa et al., 2017), and be responsible for leukemic progression in patients with MDS, mainly for AML (Hosono et al., 2014).

We also observed the occurrence of mosaic monosomy of chromosome $\mathrm{X}$ in a patient whose MDS was stable at the end of the study. The acquired loss of a sex chromosome is a phenomenon related to aging and can be associated with hematological malignancies in some settings (Bacher et al., 2015). In MDS, the loss of chromosome $X$ only is reported in approximately $0.2-0.3 \%$ of patients, whereas the monosomy of $\mathrm{X}$ in combination with other chromosomal abnormalities can be detected in up to $1.5 \%$ of patients. These findings correlate with an intermediate risk prediction (Schanz et al., 2012; Zahid et al., 2017), which is in agreement with the case in our present study. The loss of chromosome $\mathrm{Y}$ is a frequent finding in patients with MDS (Bacher et al., 2015). The aneuploidy of chromosome $\mathrm{Y}$ in the hematopoietic progression in MDS is classified as having a very good prognosis (Zahid et al., 2017). In agreement with this, our patient with the loss of chromosome $\mathrm{Y}$ presented a very good cytogenetic risk and with stable disease at the end of the study.

In 14 patients of our cohort with expandable clones, the karyotype of the patients did not show numerical and/or structural chromosomal alterations. Moreover, in three patients of the original cohort, it was not possible to clonally expand the cells of the bone marrow for further cytogenetic analysis. Since MDS is composed of a group of heterogeneous diseases, it is important to investigate cases of primary MDS using other genomic analysis methodologies of medical interest, including chromosome analysis by single nucleotide polymorphism microarrays and exome sequencing, studies that may provide a contribution to the adequate characterization of the MDS phenotype and to improve the quality of prognostic stratification, to direct and personalize the patient's treatment and to identify potential therapeutic targets (Forsberg, et al., 2012; Macedo et al., 2015, Ganguly \& Kadam, 2016). The data generated with new methodologies would be useful for elucidating the mechanisms underlying the etiology and progression of MDS and to guide future sub-classifications, which can positively influence the management and treatment of affected patients.

\section{CONCLUSIONS}

We identified chromosomal alterations that are important in MDS. By comparing our cytogenetic findings with information deposited in databases and in the literature, we 
could show that such alterations are associated with important biological mechanisms for hematopoiesis Although our sample size was small, this study can contribute with the MDS databases and MDS epidemiological record of central Brazil. Furthermore, our results support the hypothesis that cytogenetic risk (IPSS-R) is an important informative variable to infer prognostic risk and help in the therapeutic follow up of patients with this oncohematological disorder.

Conventional cytogenetics is a screening test that is relatively low cost and it remains important for the identification of numerical and structural chromosomal alterations associated with MDS and for predicting risk for patients. However, it is not yet possible to establish a direct relationship between karyotype findings and MDS outcomes, given the complex, variable, and heterogeneous nature of this disease, both clinically and in laboratory findings.

\section{ACKNOWLEDGMENTS}

CLR is grateful for the scholarships granted by the Foundation for Research Support of the state of Goiás (FAPEG-GO) and Coordination for the Improvement of Higher Education Personnel (Capes) and for the support provided to the study by FAPEGGO.

\section{AUTHOR CONTRIBUTIONS}

C.L.R., I.P.P., L.B.M., A.D.C. and C.C.S. designed the study. F.S.M.K. was the patient's attending physician. C.L.R., I.P.P., M.O.D. and D.M.C.C. performed the experiments. C.L.R., I.P.P., L.B.M., A.D.C. and C.C.S. analyzed data and performed the statistical analysis. C.L.R., I.P.P. and A.D.C. contributed to manuscript writing. All authors read and approved the final manuscript.

\section{CONFLICTS OF INTEREST}

The authors declare no conflict of interest.

\section{REFERENCES}

Adès L, Itzykson $\mathrm{R}$ and Fenaux P (2014). Myelodysplastic syndromes. Lancet. 383: 2239-2252. https://doi.org/10.1016/S0140-6736(13)61901-7

Alfaro R, Perez-Granero A, Duran MA, Besalduch J, et al. (2008). dup(1)(q21q32) as a sole cytogenetic event is associated to a leukemic transformation in myelodysplastic syndromes. Leuk. Res. 32: 159-161. https://doi.org/10.1016/j.leukres.2007.03.033

Bacher U, Schanz J, Braulke F and Haase D (2015). Rare cytogenetic abnormalities in myelodysplastic syndromes. Mediterr. J. Hematol. Infect. Dis. 7: e2015034. https://doi.org/10.4084/MJHID.2015.034

Bănescu C, Benedek I, Duicu C, Demian S, et al. (2011). Cytogenetic findings and their prognostic impact in myelodysplastic syndrome patients. Rev. Română Med. Lab. 19: 139-147.

Bejar R (2013). Prognostic models in myelodysplastic syndromes. Hematology Am. Soc. Hematol. Educ. Program 2013: 504-510. https://doi.org/10.1182/asheducation-2013.1.504

Bejar R, Stevenson K, Abdel-Wahab O, Galili, N, et al. (2011). Clinical effect of point mutations in myelodysplastic syndromes. N. Engl. J. Med. 364: 2496-2506. https://doi.org/10.1056/NEJMoa1013343

Bernasconi P, Alessandrino EP, Boni M, Bonfichi M, et al. (1994). Karyotype in myelodysplastic syndromes: relations to morphology, clinical evolution, and survival. Am. J. Hematol. 46: 270-7. 
Butrym A, Lech-Maranda E, Patkowska E, Kumiega B, et al. (2015). Polish experience of lenalidomide in the treatment of lower risk myelodysplastic syndrome with isolated $\operatorname{del}(5 \mathrm{q}) . \quad B M C$ Cancer. $15: 508$. https://doi.org/10.1186/s12885-015-1444-1

Cazzola M and Malcovati L (2010). Prognostic classification and risk assessment in myelodysplastic syndromes. Hematol. Oncol. Clin. North Am. 24: 459-468. https://doi.org/10.1016/j.hoc.2010.02.005

Christiansen DH, Andersen MK and Pedersen-Bjergaard J (2004). Mutations of AML1 are common in therapy-related myelodysplasia following therapy with alkylating agents and are significantly associated with deletion or loss of chromosome arm 7q and with subsequent leukemic transformation. Blood. 104: 1474-1481. https://doi.org/10.1182/blood-2004-02-0754

Dao KT (2017). Myelodysplastic Syndromes: Updates and Nuances. Med. Clin. North Am. 101(2): 333-350. https://doi.org/10.1016/j.mcna.2016.09.006.

Eisenmann KM, Dykema KJ, Matheson SF, Kent NF, et al. (2009). 5q- myelodysplastic syndromes: chromosome 5q genes direct a tumor-suppression network sensing actin dynamics. Oncogene. 28: 3429-3441. https://doi.org/10.1038/onc.2009.207

Emerenciano M, Barbosa TC, Lopes BA, Blunck CB, et al. (2014). Brazilian Collaborative Study Group of Infant Acute Leukemia. ARID5B polymorphism confers an increased risk to acquire specific $M L L$ rearrangements in early childhood leukemia. BMC Cancer. 14: 127. https://doi.org/10.1186/1471-2407-14-127

Estephan F and Tiu RV (2014). Current and novel therapeutic approaches in myelodysplastic syndromes. J. Community Support Oncol. 12: 236-249. https://doi.org/10.12788/jcso.0057

Feng X, Scheinberg P, Wu CO, Samsel, L, et al. (2011). Cytokine signature profiles in acquired aplastic anemia and myelodysplastic syndromes. Haematologica. 96: 602-606. https://doi.org/10.3324/haematol.2010.030536

Font P, Loscertales J, Benavente C, Bermejo A, et al. (2013). Inter-observer variance with the diagnosis of myelodysplastic syndromes (MDS) following the 2008 WHO classification. Ann. Hematol. 92: 19-24. https://doi.org/10.1007/s00277-012-1565-4

Forsberg LA, Hamid CR, Razzaghian R, Pakalapati G, et al. (2012). Age-Related Somatic Structural Changes in the Nuclear Genome of Human Blood Cells. The American Journal of Human Genetics. 90: 217-228. https://doi.org/10.1016/j.ajhg.2011.12.009

Giagounidis A and Haase D (2013). Morphology, cytogenetics and classification of MDS. Best Pract. Res. Clin. Haematol. 26: 337-353. https://doi.org/10.1016/j.beha.2013.09.004

Gologan R (2010). Demo-geographical data of myelodysplastic syndrome based on a large sample of patients from a Romanian Hematological Center. J. Buon. 15: 547-555.

Gómez-Seguí I, Makishima H, Jerez A, Yoshida K, et al. (2013). Novel recurrent mutations in the RAS-like GTPbinding gene RIT1 in myeloid malignancies. Leukemia. 27: 1943-1946. https://doi.org/10.1038/leu.2013.179

Greenberg PL, Tuechler H, Schanz J, Sanz G, et al. (2012). Revised international prognostic scoring system for myelodysplastic syndromes. Blood. 120: 2454-2465. https://doi.org/10.1182/blood-2012-03-420489

Grimwade D, Hills RK, Moorman AV, Walker H, et al. (2010). Refinement of cytogenetic classification in acute myeloid leukemia: determination of prognostic significance of rare recurring chromosomal abnormalities among 5876 younger adult patients treated in the United Kingdom Medical Research Council trials. Blood. 116: 354-365. https://doi.org/10.1182/blood-2009-11-254441

Haase D (2008). Cytogenetic features in myelodysplastic syndromes. Ann Hematol. 87: 515-526. https://doi:10.1007/s00277-008-0483-y

Hasegawa N, Oshima M, Sashida G, Matsui H, et al. (2017). Impact of combinatorial dysfunctions of Tet2 and Ezh2 on the epigenome in the pathogenesis of myelodysplastic syndrome. Leukemia. 31: 861-871. https://doi.org/10.1038/leu.2016.268

Heuser M, Yap DB, Leung M, Algara TR, et al. (2009). Loss of MLL5 results in pleiotropic hematopoietic defects, reduced neutrophil immune function, and extreme sensitivity to DNA demethylation. Blood. 113: 1432-1443. https://doi.org/10.1182/blood-2008-06-162263

Hosono N, Makishima H, Jerez A, Yoshida K, et al. (2014). Recurrent genetic defects on chromosome 7q in myeloid neoplasms. Leukemia. 28: 1348-1351. https://doi.org/10.1038/leu.2014.25

Jasek M, Gondek LP, Bejanyan N, Tiu R, et al. (2010). TP53 mutations in myeloid malignancies are either homozygous or hemizygous due to copy number-neutral loss of heterozygosity or deletion of 17p. Leukemia. 24: 216-219. https://doi.org/10.1038/leu.2009.189

Komrokji RS, Padron E, Ebert BL and List AF (2013). Deletion 5q MDS: molecular and therapeutic implications. Best Pract. Res. Clin. Haematol. 26: 365-375. https://doi.org/10.1016/j.beha.2013.10.013

Lubeck DP, Danese M, Jennifer D, Miller K, et al. (2016). Systematic literature review of the global incidence and prevalence of myelodysplastic syndrome and acute myeloid leukemia. Blood. 128: 5930.

Malcovati L, Hellstrom-Lindberg E, Bowen D, Adès L, et al. (2013). Diagnosis and treatment of primary myelodysplastic syndromes in adults: recommendations from the European LeukemiaNet. Blood. 122: 2943-2964. https://doi.org/10.1182/blood-2013-03-492884 
Neukirchen J, Schoonen WM, Strupp C, Gattermann N, et al. (2011). Incidence and prevalence of myelodysplastic syndromes: data from the Düsseldorf MDS-registry. Leuk. Res. 35: 1591-1596. https://doi.org/10.1016/j.leukres.2011.06.001

Nomdedeu M, Calvo X, Pereira A, Carrió A, et al. (2016). Prognostic impact of chromosomal translocations in myelodysplastic syndromes and chronic myelomonocytic leukemia patients. A study by the Spanish group of myelodysplastic syndromes. Genes Chromosomes Cancer. 55: 322-327. https://doi.org/10.1002/gcc.22333

Papaemmanuil E, Gerstung M, Malcovati L, Tauro S, et al. (2013). Clinical and biological implications of driver mutations in myelodysplastic syndromes. Blood. 122: 3616-3627. https://doi.org/10.1182/blood-2013-08-518886

Peterson JF, Baughn LB, Pearce KE, Williamson CM, et al. (2018). KMT2A (MLL) rearrangements observed in pediatric/young adult T-lymphoblastic leukemia/lymphoma: a 10-year review from a single cytogenetic laboratory. Genes Chromosomes Cancer. 57: 541-546. https://doi.org/10.1002/gcc.22666

Prebet T, Gore SD, Esterni B, Gardin C, et al. (2011). Outcome of high-risk myelodysplastic syndrome after azacitidine treatment failure. J. Clin. Oncol. 29: 3322-3327. https://doi.org//10.1200/JCO.2011.35.8135

Schanz J, Tuchler H, Sole F, Mallo M, et al. (2012). New comprehensive cytogenetic scoring system for primary myelodysplastic syndromes (MDS) and oligoblastic acute myeloid leukemia after MDS derived from an international database merge. J. Clin. Oncol. 30: 820-829. https://doi.org/10.1200/JCO.2011.35.6394

Shih AH, Chung SS, Dolezal EK, Zhang SJ, et al. (2013). Mutational analysis of therapy-related myelodysplastic syndromes and acute myelogenous leukemia. Haematologica. 98: 908-912. https://doi.org/10.3324/haematol.2012.076729

Sloand EM, Mainwaring L, Fuhrer M, Ramkissoon S, et al. (2005). Preferential suppression of trisomy 8 compared with normal hematopoietic cell growth by autologous lymphocytes in patients with trisomy 8 myelodysplastic syndrome. Blood. 106: 841-851. https://doi.org/10.1182/blood-2004-05-2017

Sloand EM, Pfannes L, Chen G, Shah S, et al. (2007). CD34 cells from patients with trisomy 8 myelodysplastic syndrome (MDS) express early apoptotic markers but avoid programmed cell death by up-regulation of antiapoptotic proteins. Blood. 109: 2399-2405. https://doi.org/10.1182/blood-2006-01-030643

Sole F, Luno E, Sanzo C, Espinet B, et al. (2005). Identification of novel cytogenetic markers with prognostic significance in a series of 968 patients with primary myelodysplastic syndromes. Haematologica. 90: 1168-1178.

Steidl C, Steffens R, Gassmannb W, Hildebrandt B, et al. (2005). Adequate cytogenetic examination in myelodysplastic syndromes: analysis of 529 patients. Leuk. Res. 29: 987-993. https://doi.org/10.1016/j.leukres.2005.01.019

Verma RS and Babu A (1995). Human chromosomes: principles and techniques. McGraw-Hill, McGraw-Hill, New York 1995.

Visconte V, Avishai N, Mahfouz R, Tabarroki A, et al. (2015). Distinct iron architecture in SF3B1-mutant myelodysplastic syndrome patients is linked to an SLC25A37 splice variant with a retained intron. Leukemia. 29: 188-195. https://doi.org/10.1038/leu.2014.170

Zahid MF, Malik UA, Sohail M, Hassan IN, et al. (2017). Cytogenetic abnormalities in myelodysplastic syndromes: an overview. Int. J. Hematol. Oncol. Stem Cell Res. 11: 231-239. 